\title{
Marjolin's Ulcer at the Kara Teaching Hospital (Togo)
}

\section{Tchaa Hodabalo Towoezim1, Tamegnon Dossouvi2 ${ }^{*}$, Yaovi Yanick Dellanh ${ }^{3}$, Kokou Kanassoua ${ }^{2}$, Irokoura Kassegne4, Pio-Faré Gnandi1, Anani Abalo5, Ekoué David Dosseh6}

\author{
${ }^{1}$ Department of Traumatology, Teaching Hospital of Kara, University of Kara, Kara, Togo \\ ${ }^{2}$ Department of General Surgery, Teaching Hospital of Kara, University of Kara, Kara, Togo \\ ${ }^{3}$ Department of Traumatology, Regional Hospital of Sokodé, University of Lomé, Lomé, Togo \\ ${ }^{4}$ Department of General Surgery, Regional Hospital of Kara, University of Kara, Kara, Togo \\ ${ }^{5}$ Department of Traumatology, Sylvanus Olympio Teaching Hospital of Lomé-Togo, University of Lomé, Lomé, Togo \\ ${ }^{6}$ Department of General Surgery, Sylvanus Olympio Teaching Hospital of Lomé-Togo, University of Lomé, Lomé, Togo \\ Email: ^dboris@yahoo.fr
}

How to cite this paper: Towoezim, T.H., Dossouvi, T., Dellanh, Y.Y., Kanassoua, K., Kassegne, I., Gnandi, P.-F., Abalo, A. and Dosshe, E.D. (2022) Marjolin's Ulcer at the Kara Teaching Hospital (Togo). Surgical Science, 13, 34-39.

https://doi.org/10.4236/ss.2022.131006

Received: September 17, 2021

Accepted: January 22, 2022

Published: January 25, 2022

Copyright $\odot 2022$ by author(s) and Scientific Research Publishing Inc. This work is licensed under the Creative Commons Attribution International License (CC BY 4.0).

http://creativecommons.org/licenses/by/4.0/

\begin{abstract}
Marjolin's ulcer is an aggressive tumor that occurs on a chronic non-healing wounds or burn scars. It's a rare disease. Histologically, it is most often a squamous cell carcinoma. The real frequency is not known. Its incidence would be higher in developing countries where ancestral beliefs and financial difficulties cause consultation delays. Thus the diagnosis is delayed, due in part to the lack or insufficiency of diagnostic means. Our study aimed to describe the epidemiological, diagnostic and therapeutic particularities through three cases treated in our center. The delay in consultation resulted in the death of one patient, while for the other two, amputation prevented the extension of the tumor. Limb amputation is increasingly rare in the management of Marjolin's ulcer, but in our difficult conditions it is still widely practiced when the tumor is localized at the extremity of the limb, without signs of remote invasion.
\end{abstract}

\section{Keywords}

Ulcer, Marjolin, Cancer, Squamous Cell Carcinoma, Amputation

\section{Introduction}

Marjolin's ulcer is an aggressive malignant tumor that occurs in chronic, non-healing wounds [1]. These lesions may be due to trauma or any other cause of a chronic inflammatory reaction on the skin such as burn scars [2] [3]. It is a rare disease. The current frequency is not known, but the incidence of malignant 
degeneration on burn scar is approximately $0.77 \%-2 \%$ of burn lesions [4]. Our study aimed to describe the epidemiological, diagnostic, and therapeutic features of Marjolin's ulcer through three cases.

\section{Observation 1}

A 37-year-old teacher presented with a recurrent ulcer in his left armpit. In his history, he had a thermal burn to his left armpit which has been successfully treated at a health center 28 years ago. A year before this last consultation, there was an ulceration of the burn scar but there was not a good treatment. With the aggravation of this new ulceration, associated with the deterioration of the general condition and the appearance of paraplegia, the patient decided to consult. A biopsy revealed a squamous cell carcinoma. The extension assessment carried out made it possible to find a vertebral location of the tumor. We did local care and symptomatic treatment. The course was unfavorable, with the death of the patient (Figure 1).

\section{Observation 2}

A 42-year-old housewife, with a history of burns in her left leg 15 years ago and scarred, presented for an ulceration that appeared on this burn scar that has been evolving for five years without complete healing. We performed a biopsy with histology which revealed a squamous cell carcinoma. There were no distant metastases. Treatment consisted of trans femoral amputation, and the outcome was favorable (Figure 2).

\section{Observation 3}

This involved a 50-year-old housewife admitted with an ulcerative-budding lesion of the left leg which had progressed for 6 years. A biopsy with histology revealed the squamous cell carcinoma. There was no distant metastasis. A trans femoral amputation was performed, there was no problem postoperatively (Figure 3).

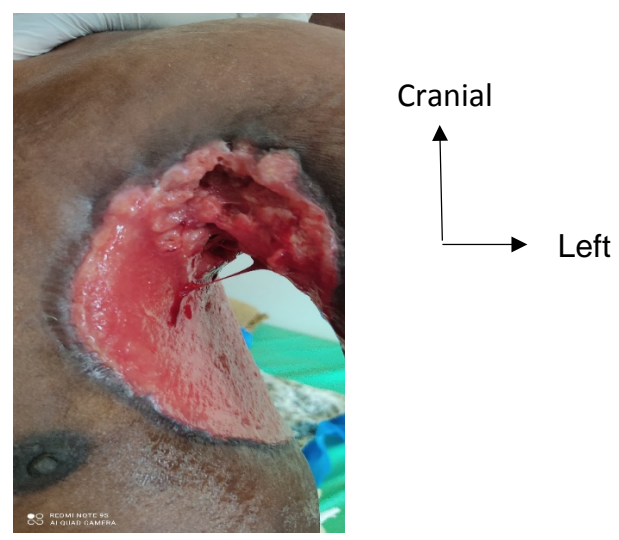

Figure 1. Ulcer occupying the entire left armpit appeared on burn scar from 28 years old, in a 37-year-old patient. 

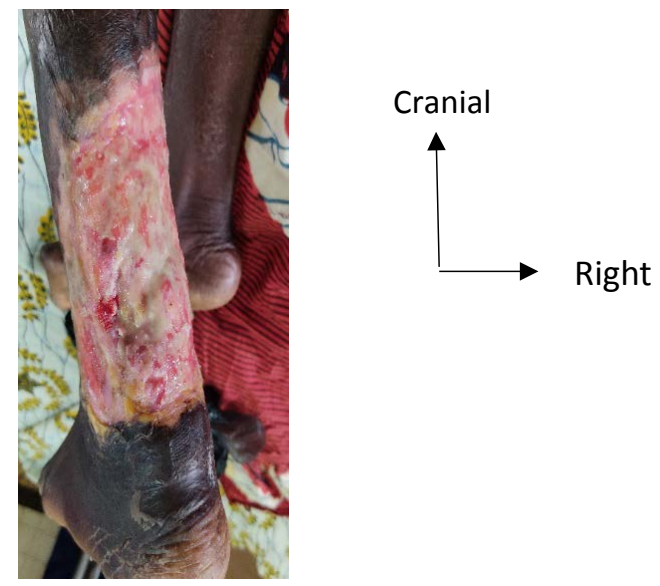

Figure 2. Ulcer on the posterior side of the left leg appeared 5 years ago on a burn scar that was 15 years old, in a 42 -year-old patient.
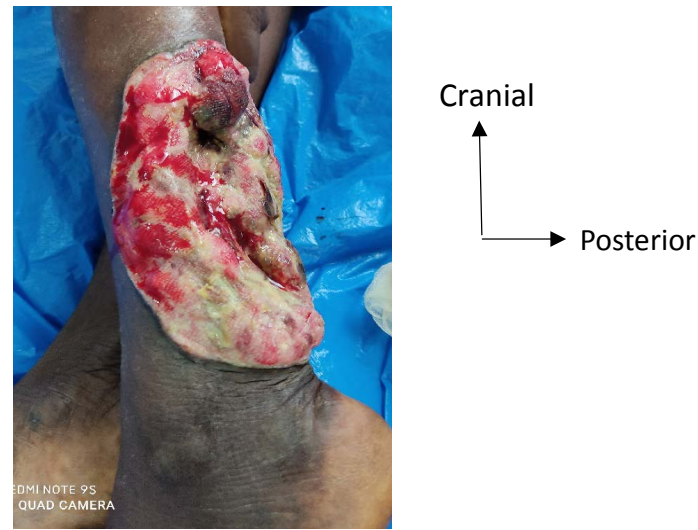

Figure 3. Ulcer appeared 5 years ago on the postero-inferior surface of the left leg, no-healing, in a 50 -years-old patient.

\section{Discussion}

Marjolin's ulcer is rare, as for the incidence rates, its affects from $0.77 \%$ to $2 \%$ of all burn scars [4]. It is more common in developing countries given the role of chronic wounds arising from situations that involve suboptimal management at time of primary injury [1]. In five years, we have received 3 cases. The delay in consultation due to ancestral beliefs and financial difficulties explain this low frequency in our case. It is a cancer that most commonly affects patients in the 5th decade, and men are the most affected [5]. It is a multifactorial and poorly understood pathology. For several years, Marjolin's ulcer referred to a burn scar tumor [6]. Currently it is defined as an aggressive skin cancer that develops in previously damaged areas or those affected by chronic inflammation. It most often develops in deep burn wounds where the healing process is slow and secondary in nature [5]. It may also develop in scar tissues of other origins and as a result of chronic tissue injury associated for instance with chronic osteomyelitis in sinuses, post-traumatic wounds, decubitus ulcers, and chronic fistulas [4]. Various aetiological factors are responsible for malignant transforma- 
tion. These include areas of chronic scar tissues that may lose cells of immune system constituting part of skin physiology. Due to this, malignant cells may avoid immunological detection and may become more aggressive and prone to metastasis [7] [8]. Also, blood vessels and lymphatics regenerate poorly. Scar tissues than becomes an immunologically crippled site where tumor cells can escape the immunological elimination processes [6]. Chronic irritation and repeated attempts to treat the wound over time may stimulate cell proliferation and increase the speed of spontaneous mutation. Toxins released by necrotic tissue may produce direct mutagenic effects in cells [5].

There is a lag period between the development of Marjolin's ulcer in a scar tissue and the time of injury. It has been observed that the latency is inversely proportional to the patients' age. Malignant transformation is delayed in younger injury victims. The older the patient at the time of injury the shorter the lag period [6]. In the literature, the average latency period varies between 28 and 36 years. The reported threshold values ranged from four weeks to 75 years [1] [6] [9]. There are several predictors of malignant transformation. These are localization on a joint or a flexion fold, localization in the lower limbs, local trauma such as friction and irritation, multiple infectious episodes, the action of irritating detergents and various local topicals [9]. The most commonly affected sites are lower extremities (53.3\% of cases), upper extremities (18.7\% of cases), torso (12.4\%), face and nape (5.8\%) [5]. In the event of a chronic or recurrent ulceration, a surgical biopsy is recommended to confirm the malignant transformation of the scar, and to determine its histological type. In most cases, histologically, Marjolin's ulcer is a squamous cell carcinoma (73\%), followed by basal cell carcinoma (10\%) [4].

Prevention remains the best treatment through adequate management of burn wounds and other ulcerative lesions by performing excision followed by graft [6] [10]. When malignant transformation occurs, surgery, especially excision, forms the backbone of treatment of Marjolin's ulcer [1]. This excision should include a $3-4 \mathrm{~cm}$ margin of normal skin with muscle and fascia due to the high metastatic potential and recurrence tendency [6]. Defects are usually skin grafted either with free flaps or splits-thickness skin grafts [5] [6]. When the lesion is located at the end of a limb, amputation may be performed, although this is increasingly rare. In the series reported from 1995 to $1999,58 \%$ of surgical treatment consisted of amputation. However, from 2000 to 2010, amputation represented only $12 \%$ of surgical cases [1]. If there is a clinically palpable lymphadenopathy, lymph node dissection is recommended with an exception for malignant melanoma, when the sentinel lymph node biopsy should be performed regardless of the presence of enlarged lymph nodes [11]. Metastases are the most important prognostic factor; regional may affect $20 \%$ to $66 \%$ of cases, and distant in $14 \%$ at the time of diagnosis [5] [12]. The role of radiotherapy and chemotherapy in the treatment of Marjolin's ulcer is not yet fully understood. In the meta-analysis by Abdi et al., in 465 treated patients, radiotherapy was used in only $2 \%$ of cases and chemotherapy in less than $1 \%$ of cases 
[1]. In case where surgery is impossible or inadequate, radiotherapy alone or combined with chemotherapy should be performed [13].

\section{Conclusion}

Marjolin's ulcer is a rare malignant tumor. In Africa, due to the delay or denied in consultation, its frequency is not known, but it would be higher than in high income countries. The few patients who consult are seen at an advanced stage, often with distant invasions. When the lesion is located at the end of the limb and there is no remote metastasis, amputation remains the method of choice in our context to prevent tumor extension.

\section{Compliance with Ethical Standards}

We have obtained the consent of patients or their families for the publication of these cases.

\section{Conflicts of Interest}

The authors declare that they have no conflict of interest.

\section{References}

[1] Abdi, M.A., Yan, M. and Hanna, T.P. (2020) Systemic Review of Modern Case Series of Squamous Cell Cancer Arising in a Chronic Ulcer (Marjolin's Ulcer) of the Skin. JCO Global Oncology, 6, 809-818. https://doi.org/10.1200/GO.20.00094

[2] Yu, N., Long, X., Lujan-Hernandez, J.R., Bai, M., Wang, Y., Wang, X. and Zhao, R. (2013) Marjolin's Ulcer: A Preventable Malignancy Arising from Scars. World Journal of Surgical Oncology, 11, 313. https://doi.org/10.1186/1477-7819-11-313

[3] Saaiq, M. and Ashraf, B. (2014) Marjolin's Ulcer in the Post-Burned Lesions and Scars. World Journal of Clinical Case, 2, 507-514. https://doi.org/10.12998/wicc.v2.i10.507

[4] Copcu, E. (2009) Marjolin's Ulcer: A Preventable Complication of Burns? Plastic and Reconstructive Surgery, 124, 156 ${ }^{\mathrm{e}}-164^{\mathrm{e}}$. https://doi.org/10.1097/PRS.0b013e3181a8082e

[5] Bazalinski, D., Przybek-Mita, J., Baranska, B. and Wiech, P. (2017) Marjolin's Ulcer in Chronic Wounds: Review of Available Literature. Contemporary Oncology, 21, 197-202. https://doi.org/10.5114/wo.2017.70109

[6] Ochenduszkiewicz, U., Matkowski, R., Szynglarewicz, B. and Kornafel, J. (2006) Marjolin's Ulcer: Malignant Neoplasm. Reports of Practical Oncology and Radiotherapy, 11, 135-138. https://doi.org/10.1016/S1507-1367(06)71058-6

[7] Bostwick 3rd, J., Pendergrast Jr., W.J. and Vasconez, L.O. (1976) Marjolin's Ulcer: An Immunologically Privileged Tumor? Plastic and Reconstructive Surgery, 57, 66-69. https://doi.org/10.1097/00006534-197601000-00013

[8] Kerr-Valentic, M., Samimi, K., Rohlen, B., et al. (2009) Marjolin's Ulcer: Modern Analysis of an Ancient Problem. Plastic and Reconstructive Surgery, 123, 184-191. https://doi.org/10.1097/PRS.0b013e3181904d86

[9] Lefebre, P., Rouge, D., Chavoin, J.P. and Costagliola, M. (1991) Dégénérescence des cicatrices: À propos de quatorze observations. Annales de Chirurgie Plastique Esthéti$q u, 36,330-335$. 
[10] Aydogdu, E., Yildirim, S. and Akoz, T. (2005) Is Surgery an Effective and Adequate Treatment in Advanced Marjolin's Ulcer. Burns, 31, 421-431.

https://doi.org/10.1016/j.burns.2005.02.008

[11] Copcu, E., Aktas, A., Sisiman, N. and Oztan, Y. (2003) Thirty-One Cases of Marjolin's Ulcer. Clinical and Experimental Dermatology, 28, 138-141.

https://doi.org/10.1046/j.1365-2230.2003.01210.x

[12] Khan, K., Giannone, A.L., Mehrabi, E., Khan, A. and Giannone, R.E. (2016) Marjolin's Ulcer Complicating a Pressure Score: The Clock Is Ticking. American Journal of Case Reports, 17, 111-114. https://doi.org/10.12659/AJCR.896352

[13] Kowal-Vern, A. and Criswell, B.K. (2005) Burn Scar Neoplasms: A Literature Review and Statistical Analysis. Burns, 31, 403-413.

https://doi.org/10.1016/j.burns.2005.02.015 